\title{
Cinema no Amazonas
}

\author{
SELDA VALE DA COSTA \\ e NARCISO JULIO FREIRE LOBO
}

OM A INVENÇÃo da máquina que produzia imagens em movimento, em 1896, na França, aventureiros deslocaram-se para diferentes lugares do mundo buscando "vistas" exóticas para serem mostradas para o público europeu, sedento por conhecer povos e paisagens, antes pintadas por viajantes e cientistas e, depois, retratadas pela fotografia. A grande novidade agora era que pessoas e imagens estavam em movimento. Nascia o cinema. A região amazônica e seu grande rio estiveram, desde o início, sob o foco e enfoque dessa nova engenhoca tecnológica.

A primeira sessão de cinema em Manaus deu-se em abril de 1897, no Teatro Amazonas. Nas primeiras décadas do século XX, a região foi percorrida por dezenas de exibidores ambulantes de empresas famosas como a Pathé-Frères e a Gaumont, que realizaram tomadas da selva e do cotidiano das cidades amazônicas, ao mesmo tempo em que estimularam o aparecimento de inúmeras salas fixas de projeção pelos rios do Acre, Roraima e Rondônia. A produção amazonense, entretanto, inicia-se apenas em 1907, com vistas produzidas pela empresa Fontenelle \& Cia que se constituirá, a partir de 1912, na maior proprietária de salas de cinema de Manaus.

Com apenas catorze anos, Silvino Santos, nascido em Portugal, saiu de sua terra, em 1899, chegando a Belém e transferindo-se, em 1910, para Manaus, onde começou a trabalhar como fotógrafo. Logo foi atraído pelo cinema, por caminhos contraditórios e transversos: J. C. Arana, um dos maiores acionistas da Peruvian Amazon Rubber Company, acusado de promover massacres contra povos indígenas da região, foi processado pelas cortes de justiça de Londres e precisava apresentar material que mostrasse a sua "verdade". Essa "verdade" não teria melhor suporte do que o cinema, que mostraria a "realidade". Em Manaus, convidou o fotógrafo Silvino Santos para a empreitada. Antes, porém, ele teria que aprender a utilizar essa nova tecnologia. Foi mandado a Paris para estagiar nos estúdios da Pathé-Frères e nos laboratórios Lumière e, em 1913, realizou o documentário sobre a empresa no Putumayo.

Sensível, Silvino Santos não mais abandonou o cinema, tornando-se documentarista e realizando centenas de pequenos filmes, além de seu trabalho principal No paiz das amazonas (1922), destinado a divulgar o Estado durante as festividades comemorativas do centenário da Independência, no Rio de Janeiro, merecedor da Medalha de Ouro daquele evento. Depois de toda uma vida no Amazonas, trabalhando para o empresário J. G. Araújo, faleceu em Manaus, em 
maio de 1970, deixando doze documentários produzidos na primeira produtora de cinema local, a Amazônia Cine Films (1918-1920), dez curtas e três longas com exibição nacional e internacional, além de três dezenas de filmes "domésticos", autêntica crônica familiar da vida do empresário J. G. Araújo em Portugal e no Amazonas.

Com o declínio da borracha e dos negócios de seu patrão, Silvino viveu muitos anos na obscuridade, sendo redescoberto, em 1969, por ocasião de I Festival Norte de Cinema Brasileiro, realizado em Manaus. Tal festival, na verdade, era resultado de forte agitação cultural iniciada com a década de 1960, marcada por intensas discussões nos campos da política e das artes. Esse movimento nascia do cineclubismo, onde os grandes diretores eram revelados e objeto de polêmicas, suscitando novos candidatos a cineastas. Em Manaus, surgem Normandy Litaif, com Carniça, premiado durante o I Festival de Cinema Amador do Amazonas (1966), Ivens Lima, com Harmonia dos contrastes, que rivalizou com o trabalho de Litaif, e Almir Pereira, com Claustro escuro, todos em 1966, em $16 \mathrm{~mm}$, e que nunca mais fizeram uso da câmera. Nos dois festivais começaram a pontificar

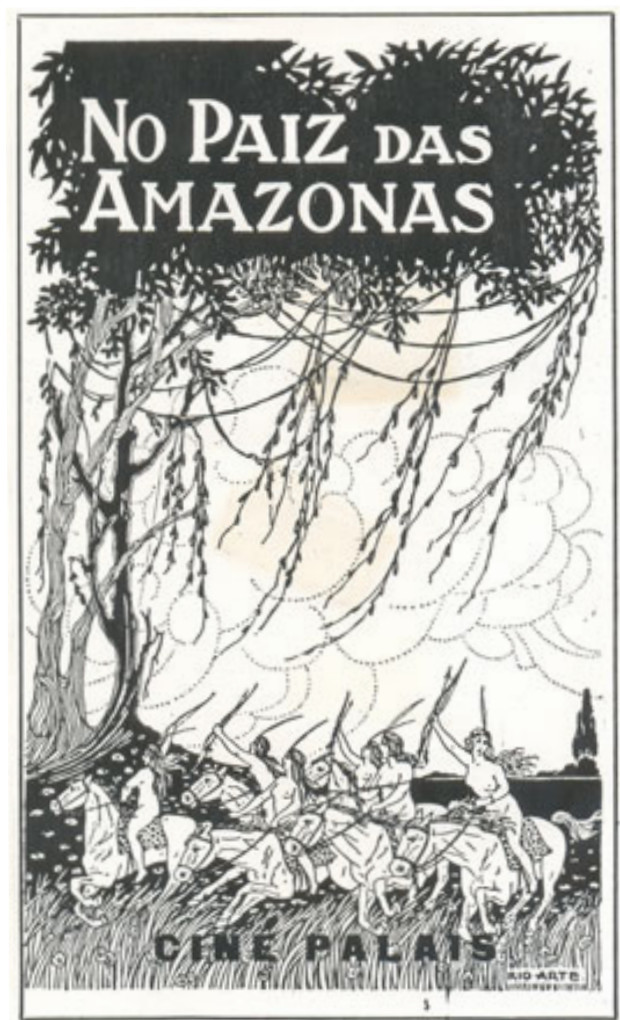

Folheto de No paiz das amazonas, 1922. também os jovens cineclubistas do Grupo de Estudos Cinematográficos, Felipe Lindoso, Roberto Kahané, Raimundo Feitosa, Aldísio Filgueiras, Djalma Batista e Domingos Demasi. O cineclubismo estimulou também a produção de uma revista de cinema, Cinéfilo (1966-1968), do crítico José Gaspar. Márcio Souza, um dos teóricos do que ele denominou de "Cinema amazônico", adaptou o romance A selva, de Ferreira de Castro, para o cinema (1972). O grande projeto, a essa altura, sob a liderança do cinéfilo Joaquim Marinho, era criar um pólo de cinema em Manaus, estabelecendo ali uma indústria capaz de atrair financiamentos no rastro dos primeiros anos da Zona Franca de Manaus. Esse projeto cultural não foi adiante, mas nos anos de 1970-1990, a produção de alguns documentários e filmes ficcionais contam com a co-participação do Estado, por meio de incentivos financeiros e logísticos. Filmes como o longa Ajuricaba, o rebelde da Amazônia (1976), do carioca Osvaldo Caldeira, ou o premiado Mater dolorosa (1980) do amazonense Roberto Evangelista e O cineasta da selva (1997) e Bocage, o triunfo do amor, ambos de 1997, dos amazonenses Aurélio Michiles e Djalma L. Batista respectivamente, são exemplos dessa parceria bem armada. 


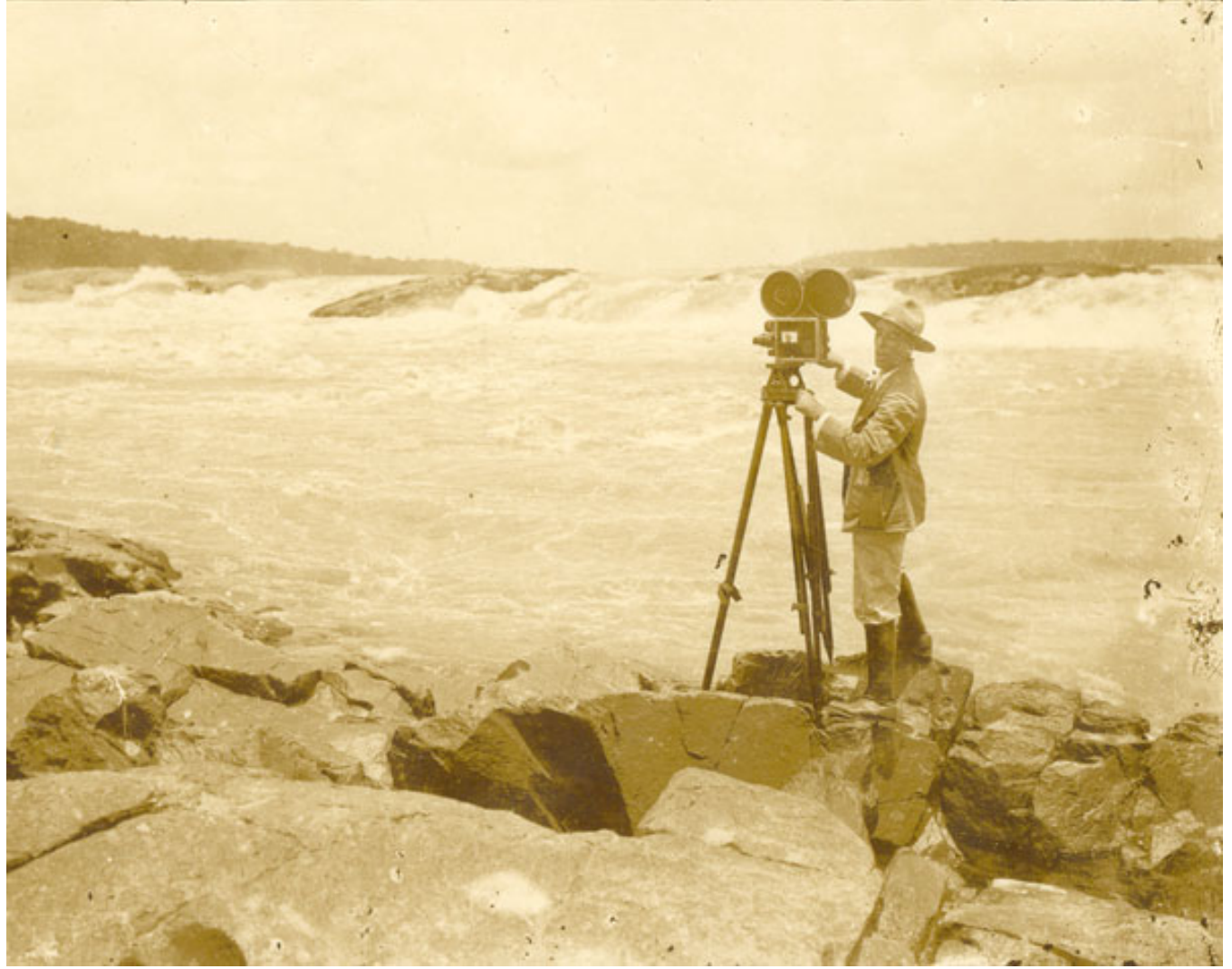

Silvino Santos filmando o Salto Teotonio, em Rondônia, 1918.

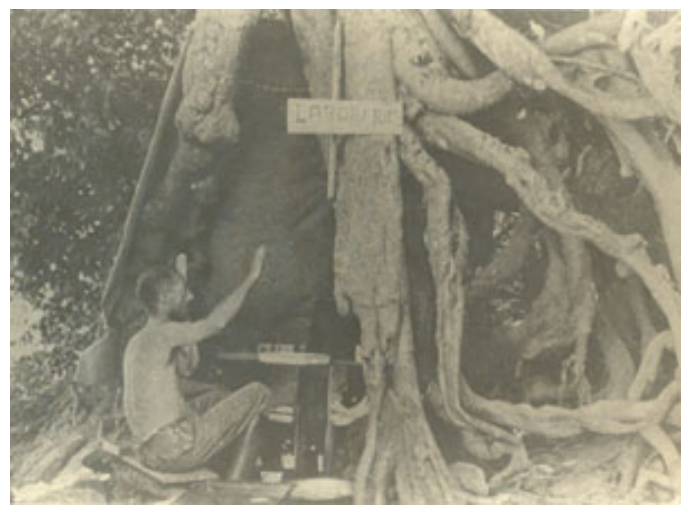

Silvino Santos em laboratório improvisado.

Em 1987, o governo promoveu também o Primeiro Festival Internacional de Cinema Amazônico e, em 2001, criou a Amazon Film Comission, que produziu frutos como Tainá Ie II. Em 2004, realizou o Amazonas Film Festival - Filme de Aventura.

A região prestou-se, no início, muito mais a um cinema documentalista que ficcional, produzindo filmes de cunho propagandístico, uma bemsucedida relação entre turismo e imagem; quase sempre um cinema fantástico, às vezes etnográfico, que acabou mais por encobrir que revelar a realidade amazônica. A região e seu estranho mundo foram cenário produzido em estúdios norte-americanos para mirabolantes imagens de monstros e mundos históricos, caçadas perigosas, formigas, aranhas e piranhas gigantes, índios canibais e caçadores de cabeças, recriando os mais desvairados mitos sobre a região. Mesmo Glauber Rocha não escapou a essa atração quando, a convite do governo militar, filmou com seu olhar visionário Amazonas, Amazonas (1966). Mas, apesar da descontinuidade parecer ser a tônica da 
atividade cinematográfica no Amazonas, o cinema (em película, vídeo e digital) produzido nos últimos anos traduz a busca de uma linguagem amazônica e de uma estilística mais sofisticada, mais universal.

Bibliografia

COSTA, Selda V. Eldorado das ilusões. Cinema e sociedade. Manaus: 1897-1935. Manaus, Editora da Universidade do Amazonas, 1997.

COSTA, Selda et alli. "Cinema na Amazônia". Revista História, Ciências, Saúde, vol. VI (suplemento), set. 2000, pp. 1073-1123.

COSTA, Selda V. e LOBO, Narciso. Hoje tem Guarany. São Paulo, Edições dos Autores, 1983.

. No rastro de Silvino Santos. Manaus, Governo do Estado, 1987.

LOBO, Narciso J. Freire. A tônica da descontinuidade. Cinema e política na década de 60. Manaus, Editora de Universidade do Amazonas, 1994.

Palavras-chave: Amazônia, Cinema, Silvino Santos.

Keywords: Amazon, Cinema, Silvino Santos.

Selda Vale da Costa é antropóloga e pesquisadora de cinema brasileiro. Professora de Ciências Sociais da Universidade Federal do Amazonas.

Narciso Julio Freire Lobo é jornalista, estudioso dos fenômenos mediáticos. Professor de Comunicação Social da Universidade Federal do Amazonas.

Texto solicitado aos autores. Recebido e aceito para publicação em 18 de janeiro de 2005 . 